\title{
Experiences of Palliative Health Care for Homeless and Vulnerably Housed Individuals
}

\author{
Eva Purkey, MD, MPH, CCFP, FCFP and Meredith MacKenzie, MD, BSc, CCFP (AM), FCFP
}

Background: Thirty-five thousand Canadians are homeless on any given night, and mortality rates are much higher than for the general population. Studies have identified barriers to accessing end-of-life care among the homeless, including logistic barriers and experiences of stigma. This study seeks to explore the experience, goals, fears, and hopes surrounding death in the setting of homelessness or vulnerable housing.

Methods: Qualitative phenomenological study involving focus groups and in-depth interviews with 31 people with lived experience of homelessness. Additional sociodemographic data collected from participants.

Findings: Themes included extensive experience with death and dying, relationship with mortality, ideas for a good death, and desires for end-of-life care. Participants presented suggestions for improving end-of-life care including care that was delivered by people with lived experience of homelessness and substance use; care that was provided either as outreach or in a welcoming, flexible institutional environment; care that minimized stigma and enhanced dignity; and care that respected people's desires to use substances at the end of life.

Discussion: Participants with lived experience of homelessness were articulate in their desires and needs for end-of-life care. They have extensive exposure to mortality and feel that their needs are not met by the current palliative care system. Recommendations for system change that include harm reduction and equityoriented health care, as well as a combination of outreach and inpatient services, are necessary before palliative care services will be accessible for this population. (J Am Board Fam Med 2019;32:858-867.)

Keywords: Canada, Delivery of Health Care, Focus Groups, Harm Reduction, Homeless Persons, Housing, Palliative Care, Qualitative Research, Substance-Related Disorders, Terminal Care

Thirty-five thousand Canadians are homeless on any given night and at least 235,000 Canadians experience homelessness in a year. ${ }^{1}$ Indigenous people are overrepresented. ${ }^{2}$ Average life expec-

This article was externally peer reviewed.

Submitted 12 March 2019; revised 4 May 2019; accepted 7 May 2019.

From the Department of Family Medicine, Queen's University, Kingston Ontario, Canada (EP, MM); Street Health Centre, a part of Kingston Community Health Centres, Kingston Ontario, Canada (MM).

Funding: Funding for this project was received by the South East Local Health Integration Network (SELHIN) in Ontario, Canada.

Conflict of interest: none declared.

Corresponding author: Eva Purkey, MD, MPH, CCFF, FCFP, Department of Family Medicine, Queen's University, 220 Bagot St, Kingston, Ontario K7L 3G2, Canada (E-mail: eva.purkey@dfm.quuensu.ca).

\section{See Related Article on Page 847.}

tancy for homeless persons is estimated to be between 42 and 52 years. $^{2}$ Mortality rates among homeless populations are much higher than the general population. ${ }^{3}$ Despite exhibiting signs and symptoms of extensive disease, homeless individuals often do not receive palliative care because of the challenges posed by their immediate environment. Between $44 \%$ and $60 \%$ of people who experience homelessness will use illicit substances in their lifetime. ${ }^{1,4,5}$ Despite a keen interest in advanced care planning ${ }^{6-8}$ and specific preferences for location of death, homeless patients often die in acute care hospital settings. ${ }^{9,10}$

Homelessness is often not experienced in the traditional or commonly understood sense (ie, one is living on the streets) and the terms, "homeless" or "vulnerably housed," can be defined to include those who live in substandard conditions not fit for human occupation; in temporary, transient, and unstable accommodations; in shelters; and/or in 
housing situations that are precarious (subject to being lost at any time). ${ }^{11}$

The barriers to accessing palliative care for people experiencing homelessness or in vulnerable housing are documented both by our study and by others. ${ }^{3,10,12-15}$ These include logistic barriers such as lack of telephone to make appointments, lack of transportation to health care services and lack of housing to receive home care, as well as care avoidance related to experiences of stigma within the health care setting. Hearing directly from people who have experienced homelessness concerning their fears and hopes about death and dying, their experiences interfacing with the health care system in the context of palliative care, and their own proposed solutions to create a palliative care system that is accessible to them has the potential to change practitioner and policy-makers' perspective on the "one size fits all" approach of traditional medical services.

Through analysis of the narratives of people with lived experience, this study, funded by the South East Local Health Integration Network in Ontario Canada, explores the goals, fears, aspirations, experiences and hopes when it comes to living and dying in the precarious setting of homelessness or vulnerable housing. Many of the study findings are consistent with the literature on homelessness and palliative care; however, our study includes novel information related to palliative care and homelessness in the context of substance use as well as participant suggestions for system redesign.

\section{Methods}

\section{Study Design}

This article reports a subset of the qualitative findings of a larger study that included a survey of health and social service providers (HSSPs), indepth interviews with HSSP key informants, as well as in-depth interviews and focus groups with people with lived experience of homelessness. These surveys and interviews occurred between January and August 2018. Data from the HSSP surveys and interviews is reported elsewhere. This project received Queen's University Health Sciences and Affiliated Teaching Hospitals Research Ethics Board approval.

\section{Participants}

Persons with experience of homelessness were recruited from agencies mandated to provide services to those who are homeless or vulnerably housed. Inclusion criteria included a past or present history of homelessness but not necessarily a history of experience with the palliative care system. It was anticipated that people who were both palliative and homeless would be a difficult to access, and that many homeless or vulnerably housed participants would have had experiences with palliative and end-of-life care through friends or relatives and would be able to effectively comment on the needs/ gaps of existing palliative-care services. Snowball sampling was used to recruit further participants. Participants completed an anonymous survey collecting basic demographic variables identified as significant ${ }^{15-18}$ including gender, ethnicity, education level, housing experience, service use, selfreported mental health and health conditions, and substance use history. Six focus groups were held with 2 to 7 participants, along with 4 in-depth interviews, all lead by research assistants or by the principle investigator. The intent was to run focus groups exclusively, but due to scheduling challenges, several participants were interviewed individually. Both interviews and focus groups used the same semistructured interview guide exploring themes related to how homelessness affects access to palliative care, the impact of substance use, thoughts on death and dying, and recommendations to improve palliative care for vulnerably housed people. Theme saturation was reached in that no new themes were appearing in the interviews and focus groups. Thirty-one people participated, and focus groups and interviews lasted between 20 and 90 minutes. Participants were given a stipend of $\$ 50$ for their participation.

\section{Data Analysis}

Quantitative survey data are reported in Table 1, Table 2, and Table 3.

This study used a phenomenological approach to explore the experience of end-of-life care among people with a lived experience of homelessness. Phenomenology allows for the exploration of shared experiences of a group of individuals around a specific topic, ${ }^{19}$ in this case, endof-life and palliative care. Researchers used a transformative framework to elevate the voices of people experiencing homelessness. ${ }^{19}$ The findings reported here relate to the in-depth inter- 
Table 1. Demographics and Housing Status

\begin{tabular}{|c|c|}
\hline Variable & $\begin{array}{l}\text { Response, } \\
\%(\mathrm{n}=31)\end{array}$ \\
\hline \multicolumn{2}{|l|}{ Age, years } \\
\hline$<21$ & 0.00 \\
\hline 21 to 29 & 6.4 \\
\hline 30 to 39 & 35.5 \\
\hline 40 to 49 & 32.3 \\
\hline 50 to 59 & 16.1 \\
\hline 60 to 69 & 9.7 \\
\hline $70+$ & 0.00 \\
\hline \multicolumn{2}{|l|}{ How to you identify? } \\
\hline Male & 58.0 \\
\hline Female & 38.7 \\
\hline Transgender & 0.0 \\
\hline Prefer not to answer & 3.3 \\
\hline \multicolumn{2}{|l|}{ What community do you live in? } \\
\hline Urban & 93.6 \\
\hline Rural & 3.2 \\
\hline Semi-rural & 3.2 \\
\hline \multicolumn{2}{|l|}{ Are you First Nations, Inuit or Metis? } \\
\hline Yes & 12.9 \\
\hline No & 83.9 \\
\hline No answer & 3.2 \\
\hline \multicolumn{2}{|l|}{ Highest level of education achieved } \\
\hline$<8$ th grade & 9.7 \\
\hline Some high school & 32.3 \\
\hline High school diploma & 16.1 \\
\hline Some college/university & 19.4 \\
\hline College/university degree & 32.3 \\
\hline \multicolumn{2}{|l|}{ Current sources of income } \\
\hline Full-time employment & 6.5 \\
\hline Part-time employment & 25.8 \\
\hline Seasonal employment & 0.0 \\
\hline Informal employment (side jobs, etc) & 0.0 \\
\hline ODSP & 48.4 \\
\hline Panhandling & 0.0 \\
\hline Investment income & 0.0 \\
\hline Ontario works & 32.2 \\
\hline Employment insurance & 0.0 \\
\hline Canada pension plan & 3.2 \\
\hline Guaranteed income supplement & 3.2 \\
\hline Old age security & 3.2 \\
\hline $\begin{array}{l}\text { Other (Comments include child tax benefit, } \\
\text { contract position, self-employed and bottle } \\
\text { collecting) }\end{array}$ & 12.9 \\
\hline No answer & 3.2 \\
\hline \multicolumn{2}{|l|}{$\begin{array}{l}\text { How many times have you been homeless in the } \\
\text { past? }\end{array}$} \\
\hline Once & 31.1 \\
\hline Twice & 24.2 \\
\hline Three times & 17.3 \\
\hline
\end{tabular}

Table 1. Continued

\begin{tabular}{|c|c|}
\hline Variable & $\begin{array}{l}\text { Response, } \\
\%(\mathrm{n}=31)\end{array}$ \\
\hline Four times & 6.9 \\
\hline Five times & 6.9 \\
\hline More than 5 times & 17.3 \\
\hline Not sure & 13.8 \\
\hline No answer & 9.7 \\
\hline \multicolumn{2}{|l|}{$\begin{array}{l}\text { How long has it been since you had a permanent } \\
\text { place to stay? }\end{array}$} \\
\hline Days & 22.6 \\
\hline Weeks & 3.2 \\
\hline Months & 9.7 \\
\hline Years & 29.0 \\
\hline $\begin{array}{l}\text { No answer (Max time reported homeless was } 7 \\
\text { years) }\end{array}$ & 38.7 \\
\hline \multicolumn{2}{|l|}{$\begin{array}{l}\text { What is preventing you from having permanent } \\
\text { housing now? }\end{array}$} \\
\hline Unemployed & 6.5 \\
\hline Not enough income & 29.0 \\
\hline Rents too high & 25.8 \\
\hline Family/relationships conflict/breakdown & 12.9 \\
\hline Eviction & 12.9 \\
\hline Mental health problems & 9.7 \\
\hline Physical health problems or disability & 9.7 \\
\hline I don't want housing & 3.2 \\
\hline \multicolumn{2}{|l|}{$\begin{array}{l}\text { Other (Comments include not enough housing } \\
\text { in the community; bad credit; utilities cost } \\
\text { too much; poor housing conditions; } \\
\text { reference/background checks preclude } \\
\text { housing) }\end{array}$} \\
\hline No answer & 25.8 \\
\hline \multicolumn{2}{|l|}{ Are you currently on a housing waitlist? } \\
\hline Yes & 26.5 \\
\hline No & 58.1 \\
\hline I don't know & 6.4 \\
\hline No answer & 16.1 \\
\hline \multicolumn{2}{|l|}{ Where will you be sleeping tonight? } \\
\hline Own home/apartment & 48.4 \\
\hline Family/friend's home & 16.1 \\
\hline Shelter & 13.1 \\
\hline Vehicle & 0.0 \\
\hline Outside & 9.7 \\
\hline I don't know & 9.7 \\
\hline \multicolumn{2}{|l|}{ Is this your first time being homeless? } \\
\hline Yes & 19.4 \\
\hline No & 38.7 \\
\hline Not applicable (ie, not currently homeless) & 35.5 \\
\hline No answer & 9.7 \\
\hline
\end{tabular}

Some responses may not add up to $100 \%$ due to multiple responses.

ODSP, Ontario Disability Support Program. 
Table 2. Service Utilization

\begin{tabular}{lc}
\hline Variable & $\begin{array}{c}\text { Response, } \\
\text { \% ( }=31)\end{array}$ \\
\hline Services used in the past 6 months & \\
Emergency department & 58.1 \\
Food bank & 54.8 \\
Health clinic & 48.4 \\
Hospital & 45.2 \\
Housing support & 45.2 \\
Soup kitchen & 45.2 \\
Legal clinic & 29.0 \\
Drop-in space & 35.5 \\
Shelters & 22.6 \\
Job training/job supports & 16.1 \\
Detox & 16.1 \\
Harm reduction services & 12.9 \\
Services to help you get ID & 12.9 \\
Rehab & 9.7 \\
No answer & 3.2 \\
Have you been in contact with any of the & \\
following in the past 6 months? & \\
Police & \\
Ambulance & \\
Probation/parole & \\
Jail/detention centre & 19.4 \\
Other (Comments included Child & \\
Services, crisis team, Sexual Assault/ & 19.4 \\
Domestic Violence unit, Addiction and & \\
Mental Health Crisis team) & \\
No answer & \\
\hline
\end{tabular}

views and focus groups with people with lived experience of homelessness.

Focus group discussions and interviews were audio-recorded and transcribed verbatim. Transcripts were analyzed using NVivo12 (QSR International, Burlington, MA). All transcripts were read in their entirety and encoded using open coding and thematic analysis into key conceptual themes by 2 separate researchers (MM and EP), family physicians with experience working with vulnerable populations. Coding and themes were then compared and reviewed to ensure consistency and validity between researchers. ${ }^{20}$

\section{Findings}

Demographic and Survey Findings (Tables 1, 2, and 3)

Thirty-one people participated in the study. Most participants were between the ages of 30 and 49 years old. Nearly all had some high school education and $32 \%$ had received college or university degrees. Thirty-two percent were employed at least
Table 3. Self-Rated Health Status and Substance Use

\begin{tabular}{cc}
\hline Variable & Response, \\
$\%(\mathrm{n}=31)$
\end{tabular}

Do you currently have any of the following health related issues?

Asthma 19.4

COPD 22.6

Cancer 16.1

Diabetes $\quad 9.7$

Heart disease $\quad 9.7$

Liver disease $\quad 9.7$

Addiction 48.4

Mental health condition $\quad 54.8$

Physical disability $\quad 25.8$

Other 22.6

No answer $\quad 9.7$

Overall how would you rate your mental health?

Excellent 6.5

Good $\quad 19.4$

Average $\quad 35.5$

Poor 22.6

Not sure 22.6

No answer $\quad 3.2$

Overall how would you rate your physical health?

Excellent $\quad 9.7$

Good 29.0

Average $\quad 35.5$

Poor 22.6

Not sure $\quad 0.0$

No answer $\quad 3.2$

Have you used any of the following substances without a prescription in the past THREE months?

Alcohol 67.7

Benzodiazepines $\quad 32.3$

Cocaine $\quad 29.0$

Crystal meth $\quad 44.9$

Amphetamines/stimulants (eg. Adderall, $\quad 19.4$ Vyvanse)

Opioids (eg. Heroin, morphine, $\quad 25.8$ hydromorphone, fentanyl)

Marijuana $\quad 51.6$

Methadone/Suboxone $\quad 25.8$

Crack 22.6

No answer 6.5

If you have been using substances, has your substance use changed in the past ONE year?

Using more $\quad 9.7$

Using less $\quad 35.5$

Using different drugs $\quad 3.2$

No different $\quad 16.1$

Not applicable $\quad 9.7$

No answer $\quad 22.6$

COPD, Chronic Obstructive Pulmonary Disease. 
part time, $48 \%$ were on Ontario Disability Support Program, and 32\% were on Ontario Works (welfare). Thirty-nine percent had been homeless for months or years, and $17 \%$ had been homeless at least 5 times. The most commonly used substances without a prescription in the past 3 months were alcohol (68\%), marijuana (52\%), crystal methamphetamine (45\%), and benzodiazepines (32\%).

\section{Thematic Analysis (Table 4)}

Among the themes related to death and palliative care, 5 themes emerged as outlined below.

\section{Experience with Death and Dying}

As anticipated, participants had extensive experience with and exposure to death. This often took the form of the death of close family members, including parents and siblings, from natural and non-natural causes, but included friends and acquaintances. A significant number had experienced the violent death of loved ones, either through suicide, unintentional overdose, or in various accidents. Many participants had witnessed death. Several people had friends who had died through perceived lack of care while incarcerated, several people had lost parents at a very early age, and several had come upon the bodies of suicide victims.

In terms of experience specific to homelessness and death, themes revolved around inadequate or unacceptable health care contributing to death. People might leave "against medical advice" only to die on the street, might be neglected or inadequately cared for within the health care system due to discrimination, or might be discharged to unsafe or unsanitary environments where they could not receive ongoing care. Participants articulated the sense of being perpetually surrounded by death or the threat of death when on the street.

One participant had himself been in a near palliative situation following a diagnosis of cancer, and vividly described the experience of receiving chemotherapy while living on the street, being kicked out of shelters because he was vomiting too much and being too sick to walk to find food.

\section{Relationship with mortality}

The extensive exposure to death and dying, often in suboptimal conditions, influenced people's perception of mortality. Several subthemes emerged within this theme, including a fear of death, or conversely a suicidality and desire to die. In addition, participants discussed religious or spiritual beliefs, and a belief in an afterlife. While this last subtheme was interesting, important, and consistent with the literature on priorities among this population, ${ }^{21}$ our findings did not meet saturation (new information continued to emerge even at the end of our interview process) and this theme will not be expanded further here.

Several participants reported that they thought about death frequently, and that they had tried to commit suicide. Others reported resuscitating friends who had overdosed only to find that this was an intentional suicide attempt. Most participants were not afraid of death but those that were articulated a fear of dying alone, which was common among participants and in stark contrast to their ideas of a "good death." Other fears included receiving inadequate care or pain medication, being resuscitated against their wishes, or being buried in an unmarked grave if there was no one to claim their body or pay for burial.

\section{A Good Death}

Participants had strong views on what a good death would look like. The vast majority did not want to die alone and wanted to die surrounded by loved ones in a state of reconciliation, with a sense that they had been important to others. Participants did not want to be a burden to survivors. Those who used substances wanted access to them at the end of their lives, with adequate pain control. Participants articulated home as an ideal space to die and failing that would prefer to die in a comfortable institution that allowed for choice and flexibility and the presence of loved ones. No one articulated wanting to die in a hospital.

\section{Experience and Desires for End-of-Life Care}

Participants painted a vivid portrait of their overall experiences of the health care system. The overwhelming majority of their reports were negative; however, these are reported in another manuscript $^{22}$ as they do not pertain specifically to palliative care.

Most participants had not experienced palliative care. Those who had had serious medical illnesses (such as cancer) and encountered barriers to care related to their lack of housing (eg, being denied various forms of treatment unless they had housing 
Table 4. Qualitative Thematic Analysis: Quotes

Theme Quotes

Experiences of death and dying

Relationship with mortality

A good death

Experience and expectations of end of life care

Dignity and Respect

Flexibility

Substance Use
I've watched a lot of people who were on the street and they're dying all around you out there anyway. It doesn't matter if they get cancer or they're dying of addictions, right. I'll call it drug addiction. (FG7RT)

We're actually talking about homeless people who are using and are dying out there on the street because of the lack of room. There's nowhere for anybody to go. (FG10RM)

Because dying outside is not fun. I've seen, and I've tripped over bodies and that. I have I've seen many people dying out there. (FG8R)

Well right now from what I understand if you're on assistance of any sort, be it even Old Age, and you have any insurance-you are, you know, the City of $[\mathrm{X}]$ will bury you in a mass grave with no markers. You don't know, it's pretty much you're a John Doe or a Jane Doe. (FG9F10)

You think about death consistently. [..] Because you don't want to be here anymore. What the hells this life going to be if you're just going to keep getting high and like letting these people just yell at you and work over you like they're a big hammer. (FG10RM5)

Oh it terrifies me because they're not going to give me pain meds. (FG7RD)

ABSOLUTELY. You nailed it. That's one of the biggest fears of people that are homeless dying, is that they're dying by themselves. (FG1I)

That would make for a pretty scary death out on the street. [..] And nobody is going to know that you passed away, nobody's gonna know, you start thinking things (FG1A)

I think we live in Hell and when we die, we don't leave this earth, we just go to another dimension and that's Heaven (FG9F10)

Compassion. Family. You know, surrounded by people who love you and you all know that you are somebody. You are part. You made- you know you touched our hearts. (FG1B)

When I'm gonna die, I'm gonna die like that [snaps his fingers] in the park with a beer and a joint in my hand. (FG1B)

Dying with friends and family around-yes. But are we all privy to that-no we're not. (FG9F10)

Yeah. Who I am. Accept me. I'm different. I am who I am. Accept me for who I am and treat me like a HUMAN BEING (FG1B)

I was just another addict. And you know the quicker I died, or, and that was the attitude. The more that died, the less they had to worry about, because we were a nuisance to society. And ah yeah it just needs to change. The stigma needs to end. (FG7RT)

It seems simple but, if that's what I've done my whole life I think, in the last stages I should be able to. You know I don't eat breakfast until, you know, 11 o'clock in the morning. I shouldn't be served lunch at noon. I probably would want lunch a little later and then I probably going to would want my dinner a little later. They seem like simple things, but this is someone's life, so for the last part of it, I think the biggest thing here is I think autonomy, right. (FG7R)

Because the way you want to die may be completely different from the way I may want to die (FG7RD)

It doesn't matter where we are in life. We all deserve autonomy to make our own decisions and actually be able to say-this is actually what I want. It doesn't matter that you don't want that for me. You're not me and I get to make my own choices, right, so. It's, I mean even when people are dying, they still get to make their own decisions, right. (FG7RL)

If somebody is dying of cancer, in extreme pain and um they're giving them pain meds and they want to inject those pain meds-they should be able to. They should be able to take their medication the way that they want to take it. You know if they want to snort it or shoot it or what have you. (FG7RD)

But if I'm on crystal meth and I'm dying of cancer and they've said to me that I'm dying anyways-I'm going to die. If I want to continue to use crystal meth in my last days, I absolutely should be able to. I make the decisions about what happens in my life not you, not you, not doctor whatever. If I made that decision I absolutely should be able to do that. Now if I made a decision to get sober, I absolutely should be able to do that too. (FG7RM)

But like if I'm using and I'm dying, I don't think I'm going to decide to get clean at that point, you know. If I'm clean-yeah I want to die a clean death, right. But if I'm using and I'm dying I'm going to say hey man get me some crack cocaine. (FG9M8) 


\begin{tabular}{|c|c|}
\hline Theme & Quotes \\
\hline \multirow[t]{5}{*}{$\begin{array}{l}\text { Proposals for improving } \\
\text { end of life care }\end{array}$} & $\begin{array}{l}\text { Other than sympathy training, I'd say rent control and guaranteed annual income would be a } \\
\text { solution to this. (FG7RN) }\end{array}$ \\
\hline & $\begin{array}{l}\text { But um if I was put in a facility where I could use and there was other people around me using, } \\
\text { I would have ended up dying and using. So I think that you should have a facility that has } \\
\text { separate parts, right. [..] So they have like transition beds and then they have rehab. Well } \\
\text { they're putting people in transitions beds and putting them in with people in rehab. Well, } \\
\text { you could trigger somebody so there has to be like section parts. (FG10RF4) }\end{array}$ \\
\hline & $\begin{array}{l}\text { So if you had a regular crew hitting a regular neighbourhood, they would know whose ailments } \\
\text { are what. If their focus was just on homeless people's health they'd be able to know Joe B is } \\
\text { at this point. Connie is at that point. And they'd be able to do the follow-up, right. And then } \\
\text { they would make arrangements because a homeless person's not going to do that. (FG9M3) }\end{array}$ \\
\hline & They need more people with lived experiences. (F7RL) \\
\hline & $\begin{array}{l}\text { There are individual rooms but there is a foyer that people can meet in. A place that they can } \\
\text { feel comfortable, maybe can have a coffee or their family there. That if someone needed to } \\
\text { visit them, they would have a common room. (FG4 mol/L) }\end{array}$ \\
\hline
\end{tabular}

or being given treatment, which was very difficult to complete without housing).

Participants' desires for end-of-life care focused on 3 areas: the desire for dignity and respect, the desire for flexibility in the care received, and the desire to use substances if they were using before the end-of-life period.

A. Dignity and Respect. The amount of stigma experienced by this group when accessing health care in general was remarkable. These negative experiences had tremendous impacts on their desires for palliative care. People felt that "society" including health care professionals, would prefer them dead, that they were viewed as a burden and as less than human, and were treated by the health care system as such. In this context, what they desired was to be treated with respect and dignity. They wanted to be taken seriously, to have their complaints addressed in a respectful and comprehensive manner, and to be shown compassion without judgment.

B. Flexibility. In addition to dignity and respect, participants wanted services that preserved their autonomy and that were flexible. They wanted freedom to choose the care received and did not want to be bound by seemingly arbitrary institutional rules (about what time to eat, when to have visitors, etc.). Several participants articulated that in the absence of this autonomy, they would elect to leave care and die on the street if necessary.

C. Substance Use. Finally, substance use was an important theme for participants. The majority of participants had used some sort of substance in the past 3 months. All of them felt that people should be allowed to continue using substances in a palliative care setting. They did articulate the need for spaces that were substance free, for those who did not use substances or who elected to stop their substance use at the end of their life. Nevertheless, they recognized that in the existing system their substance use could be a barrier not only to palliative care, but also to curative medicine (several had either themselves or had had friends who were denied care because of substance use). They also recognized that their substance use triggered the above-mentioned stigma among health care providers and they felt this was inappropriate. Almost everyone felt that regardless of institutional rules, they would continue to use their substance of choice in a palliative care setting, and that others should be allowed to do the same.

\section{Proposals for Improving End-of-Life Care}

Participants' proposals for improving palliative care closely aligned with their desires for end-of-life care.

Participants' top proposal was to improve access to affordable housing, which would allow people to access homecare and to die at home. Failing that, participants wanted an informal, comfortable space, staffed by health care providers that could support their end-of-life needs, that had a harm-reduction approach, and allowed people to experience and access care based on their own priorities. They highlighted the importance of having people with lived experience both of homelessness and of substance use as part of the palliative care system. Participants recommended improved education 
and understanding for health care providers with respect to stigma, substance use, and the impact of homelessness on health and health care access.

As an alternative to institutional care, participants recommended creating outreach programs. They discussed the informal networks of people experiencing homelessness that would assist outreach palliative care providers in locating patients, providing care, and arranging followup. They felt that there remained a group of people who would not access formal or institutional care regardless of how it was set up, and an outreach system would provide access to palliative care for this subgroup.

\section{Discussion}

Our findings highlight the connection between homelessness and mortality, both the threat of one's own mortality and the exposure to the mortality of others. Beyond this overexposure, our findings are consistent with the literature examining the desires for palliative care for people experiencing homelessness. ${ }^{8,14,21}$ It is perhaps human nature to want to be surrounded by loved ones in a state of reconciliation and to have the sense that life has been meaningful before one dies. What stands out in the priorities of our study population, is the intense prioritization of dignity and autonomy. The focus on dignity may come from personal experiences where dignity is undermined both within and outside of the health care system. The emphasis on autonomy is also important to consider. People who have experienced homelessness may be less comfortable with the rules and regulations of traditional health care models. These rules may seem arbitrary and may be delivered without explanation or understanding of the person's unique life experiences. Importantly, participants valued flexibility not only for themselves, but were explicit about valuing it for others as well, including others who would make choices different from theirs. Unconventional schedules, the use of substances, and freedom of movement were all highlighted by participants as priorities in the context of palliative care.

These findings are important because the vast majority of physicians provide care for homeless and vulnerably housed individuals, whether they know it or not. Understanding that this is a distinct population that needs to be recognized, and whose needs need to be considered in a specific way, is important in achieving the goal of health equity. A framework that can be helpful to enable us to implement these principles in health care systems is the framework of Equity-Oriented Health Care $(\mathrm{EOHC}){ }^{23} \mathrm{EOHC}$ integrates the principles of 1) trauma and violence informed care, 2) harm reduction, and 3) culturally safe care into a contextspecific care system that is tailored to address the health inequities of a specific population. This model has been used in primary care and emergency department settings and has been shown to improve comfort and confidence in care received, perceived health, certain specific health outcomes, as well as provider satisfaction. ${ }^{24}$ This model extends beyond an educational intervention to explore and implement true system change. We recommend that this model of care should permeate all health care services, but certainly those relating to an area as sensitive as palliative care.

In addition to these changes within the health care system, participants recommended outreach services for palliative care, with the involvement of people with lived experience of homelessness and/or substance use. This recommendation is also consistent with the literature. ${ }^{10,25}$ Data in this study outlines services often used by clients, which could inform locations for outreach as well as targets for education and intervention around palliative care for people experiencing homelessness.

\section{Strengths and Limitations}

As anticipated, it was difficult to recruit participants who were currently both homeless and palliative. It is possible that recruitment of this particular group would alter our findings. Nevertheless, participants in our study had extensive experience with death, with the health care system, and a few participants had themselves faced the threat of life limiting illness and so had first-hand insights into the barriers faced in this context.

A strength of our study is found in the voices of participants. A transformative framework can be used in qualitative research to raise up the voices of equity-seeking, traditionally unheard and unseen populations, ${ }^{19}$ assuming that researchers explicitly position themselves as advocates for a particular marginalized group. Even when these voices repeat messages already articulated by others, we believe that an important role of academic work is to report the direct narrative of equity-seeking peoples to inform programs, policies, and procedures that re- 
late to their care. Our study complements existing literature on substance use in palliative-care settings $^{4,26}$ by including the voices of people with lived experience.

\section{Conclusion}

Nobody gives a shit about each other. And it is like, until that changes, like the idea of somebody who is homeless dying a nice death is never going to happen. They are going to die on the corner that they sat on for the past 10 years. And that is the truth. (FG9M4)

Our findings provide a roadmap for the development, implementation, and evaluation of palliative care services that would be available, accessible, and acceptable to some of the most vulnerable in our community, using their voices to guide our efforts.

Study participants, all whom had experienced homelessness either in the present or in the past, were articulate about their needs for care. Their desires echoed what others have said in the literature. ${ }^{8,14,21}$ Participants challenge health care providers to question their own paradigms, and to ensure that they provide care that is patient centered, nonstigmatizing, and nondiscriminatory; care that embraces principles of harm reduction, flexibility, dignity, and autonomy; care that is provided outside of hospitals, either in institutions that feel as much as possible like a home, or on the street in an outreach setting for clients who are either not ready or not willing to be in an institution; care that is informed by, and to some extent provided by, people with lived experience; care that is equity-oriented and equity-enhancing for all.

\footnotetext{
The authors thank the research assistants (Megan Singh, Agniesczka Fecica, Travis Mitchell, Amanda Brierly, Regan Lavoie), and Dr Alex Leung for study design feedback. Lastly, thank you to the participants who agreed to share their deeply personal and often difficult stories to shape our understanding.
}

To see this article online, please go to: http://jabfm.org/content/ 32/6/858.full.

\section{References}

1. Roy E, Boudreau JF, Leclerc P, et al. Trends in injection drug use behaviors over 10 years among street youth. Drug Alcohol Depen 2007;89:170-175.

2. Gaetz S, Dej E, Richter T, Redma M. The state of homelessness in Canada 2016. Toronto, Canada: Canadian Observatory on Homelessness Press; 2016.
3. Huynh L, Henry B, Dosani N. Minding the gap: access to palliative care and the homeless. BMC Palliat Care 2015;14:62.

4. McNeil R Guirguis-Younger M. Illicit drug use as a challenge to the delivery of end-of-life care services to homeless persons: Perceptions of health and social services professionals. Palliat Med 2012; 26:350-359.

5. Grinman MN, Chiu S, Redelmeier DA, et al. Drug problems among homeless individuals in Toronto, Canada: prevalence, drugs of choice, and relation to health status. BMC Public Health 2010;10:94.

6. Ko E, Nelson-Becker H. Does end-of-life decision making matter? Perspectives of older homeless adults. Am J Hosp Palliat Care 2014;31:183-188.

7. Sudore RL, Cuervo IA, Tieu L, et al. Advance care planning for older homeless-experienced adults: results from the Health Outcomes of People Experiencing Homelessness in Older Middle Age study. J Am Geriatr Soc 2018;66:1068-1074.

8. Hubbell SA. Advance care planning with individuals experiencing homelessness: literature review and recommendations for public health practice. Public Health Nurs 2017;34:472-478.

9. Health Quality Ontario. Palliative Care at the End of Life 2016. 2016. Available from: https:// www.hqontario.ca/Portals/0/documents/systemperformance/palliative-care-report-en.pdf.

10. Dosani N. Living \& dying on the streets: towards palliative care equity for the homeless \& vulnerably housed in Ontario 2017. (Public Lecture).

11. Gaetz S, Barr C, Friesen A, et al. Canadian definition of homelessness. Toronto, Canada: Canadian Observatory on Homelessness Press; 2012. Available from: https://www.homelesshub.ca/sites/default/files/ COHhomelessdefinition.pdf.

12. Dosani N. Meeting the end-of-life needs of the homeless \& vulnerably housed: Taking palliative care to where patients are. June 25, 2014. Available from: http://www.stmichaelshospital.com/media/detail. php? source=hospital_news/2014/20140625b_hn.

13. Sorrell JM. Aging on the street: Homeless older adults in America. J Psychosoc Nurs Ment Health Serv 2016;54:25-29.

14. Klop HT, de Veer AJE, van Dongen, SI, et al. Palliative care for homeless people: a systematic review of the concerns, care needs and preferences, and the barriers and facilitators for providing palliative care. BMC Palliat Care 2018;17:67.

15. Hudson BF, Flemming K, Shulman C, Candy B. Challenges to access and provision of palliative care for people who are homeless: a systematic review of qualitative research. BMC Palliat Care 2016;15:96.

16. Rodrigue S. Insights on Canadian society: Hidden homelessness in Canada. November 15, 2016. Available from: https://www150.statcan.gc.ca/n1/en/pub/ 75-006-x/2016001/article/14678-eng.pdf?st $=\mathrm{zm8q}$ $4 \mathrm{ssJ}$. 
17. Thistle J. Indigenous definition of homelessness in Canada. 2017. Availabel from: https://www.homelesshub.ca/IndigenousHomelessness.

18. Longboat DM. Indigenous perspectives on death and dying. Toronto, Canada: University of Toronto; 2002. Available from: https://www.cpd.utoronto.ca/ endoflife/Modules/Indigenous \%20Perspectives \%20 on\%20Death\%20and\%20Dying.pdf.

19. Creswell JWP, Cheryl N. Qualitative inquiry and research design. Thousand Oaks, CA: SAGE Publications; 2018.

20. Pope C, Ziebland S, Mays N. Qualitative research in health care. Analysing qualitative data. BMJ 2000; 320:114-116.

21. Ko E, Kwak J, Nelson-Becker H. What constitutes a good and bad death?: Perspectives of homeless older adults. Death Stud 2015;39:422-432.

22. Purkey E, MacKenzie M. Experience of healthcare among the homeless and vulnerably housed a quali- tative study: opportunities for equity-oriented health care. Int J Equity Health 2019;28:101.

23. Browne AJ, Varcoe C, Ford-Gilboe M, et al. EQUIP Healthcare: An overview of a multi-component intervention to enhance equity-oriented care in primary health care settings. Int J Equity Health 2015; 14:152.

24. Ford-Gilboe M, Wathen CN, Varcoe C, et al. How equity-oriented health care affects health: key mechanisms and implications for primary health care practice and policy. Milbank Q 2018;96:635-671.

25. Henry B, Dosani N, Huynh L, et al. Palliative care as a public health issue: understanding disparities in access to palliative care for the homeless population living in Toronto, based on a policy analysis. Curr Oncol 2017;24:187-191.

26. McNeil R, Guirguis-Younger M. Harm reduction and palliative care: is there a role for supervised drug consumption services? J Palliat Care 2012;28:175177. 